\title{
Poesia e autografia: o auto-retrato de José Gomes Ferreira enquanto poeta militante
}

Rosa Maria Martelo

Universidade do Porto

L'autoportraitiste (...) n'est rien d'autre que son texte: il survivra par là, ou pas du tout. C'est qu'il est d'abord, et seulement, écrivain.

Michel Beaujour

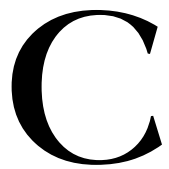

onta-se que quando Picasso mostrou a Gertrude Stein o retrato para o qual a fizera posar qualquer coisa como oitenta ou noventa vezes, a escritora se mostrou decepcionada e considerou que não estava parecido. A resposta do pintor, que na verdade refizera completamente o trabalho já sem a presença do modelo, pode conduzir-nos à questão que me proponho desenvolver. Invertendo o sentido da relação de implicação pressuposta pelo comentário de Gertrude Stein, Picasso apenas respondeu que, se o retrato não estava parecido, havia de vir a estar, sugerindo assim que, do ponto de vista da recepção, a imagem produzida nesse retrato acabaria por ocupar rigorosamente o lugar do modelo. É um comentário que parece aplicável também no caso do auto-retrato literário e, embora concordando com Michel Beaujour quanto ao facto de não haver, da parte daquele que faz um auto-retrato literário, um projecto prévio de "se pintar", ${ }_{1}$ julgo que, a partir do momento em que esse processo se instala e começa a

${ }^{1}$ BEAUJOUR, 1980, p. 341. 
desenvolver-se, ele tende, de facto, a constituir uma imagem que irá extravasar da moldura e rasurar o modelo, exactamente como Picasso previu que viria a acontecer com o retrato de Gertrude Stein.

É nesta perspectiva que me proponho abordar a construção do auto-retrato de José Gomes Ferreira enquanto poeta militante. Esse autoretrato, que se encontra disseminado por várias obras que se interrelacionam precisamente através de um mesmo efeito de autorepresentação, tende a tomar o lugar do escritor José Gomes Ferreira, e, na verdade, é este último que há-de ficar parecido com o seu auto-retrato e não o inverso.

Antes de entrar nos meandros desta questão, importa no entanto esclarecer que a sua consideração supõe aqui uma distinção entre autor textual e autor empírico, tal como é formulada por Vítor Aguiar e Silva ${ }^{2}$ e retomada por Helena Carvalhão Buescu no ensaio Em Busca do Autor Perdido. ${ }^{3}$ É importante ter presente que, do ponto de vista da recepção, o auto-retrato labora não sobre o autor empírico mas sobre "uma entidade imanente ao texto" " para compreender até que ponto esta forma de autorepresentação se caracteriza por indistinguir cuidadosamente aquelas duas categorias, apresentando o autor textual numa tal relação de continuidade com o autor empírico que a fronteira entre ambos tende a tornar-se indecidível para o leitor. Com respeito ao auto-retrato poderia dizer-se como disse Helena Buescu a propósito dos Sonetos Completos de Antero - que "o texto criaria um sujeito ficcional cuja relação com o sujeito biográfico seria de ordem metonímica. E [que] é o percurso daquele sujeito, e não deste último, que a obra então descreve". ${ }^{5}$ Todavia, no caso de José Gomes Ferreira, o texto tudo fará para dificultar esta distinção, sugerindo ao leitor que é precisamente o sujeito biográfico que é descrito na obra, quando, na verdade, o leitor apenas poderá conhecer um autor textual que se auto-retrata enquanto sujeito biográfico.

\footnotetext{
${ }^{2}$ SILVA, 1984, p. 227-231.

${ }^{3}$ BUESCU, 1998, p. 13 e 24-25.

${ }^{4}$ SILVA, 1984, p. 227.

5 BUESCU, 1994, p. 232.
} 


\section{2.}

A obra literária de José Gomes Ferreira pode ser entendida maioritariamente como um extenso auto-retrato, constituído através de um jogo de remissões extremamente elaborado e complexo. Mesmo os Diários propriamente ditos, dos quais se conhecem para já apenas três volumes, mas que deverão ascender a duas dezenas, devem ser vistos como peças a funcionar no interior dessa macro-estrutura genericamente caracterizável através da fórmula operatória que, para Michel Beaujour, define a especificidade do auto-retrato face à autobiografia: "Je ne vous raconterai pas ce que j'ai fait, mais je vais vous dire qui je suis". ${ }^{6} \mathrm{E}$ não devemos esquecer que, numa das obras fundamentais para a construção do auto-retrato de José Gomes Ferreira, A Memória das Palavras, esse tipo de diários (à data não publicados e referidos até como estando destinados a serem queimados antes da morte do escritor) surgem como objecto do discurso, sendo, por conseguinte, apontados como um material de recurso para o trabalho de escrita, uma simples fonte de informação, inacessível ao leitor e usada na construção do auto-retrato enquanto poeta. Embora haja uma componente diarística inegável na obra do escritor, à qual devemos acrescentar ainda uma vertente memorialística, ambas parecem integrar-se no processo mais vasto da construção de um auto-retrato capaz de incorporar estas duas vertentes como estratégias operativas.

Fixemos, então, uma data fundamental: 1931. Nesse ano, diz-nos José Gomes Ferreira (e não podemos esquecer que estamos já perante o auto-retrato), a escrita de um Diário Privado teria dado lugar a um outro tipo de diários a que chama "Diários em verso", os quais, diz ainda, formariam quase toda a sua obra poética. E, logo a seguir, utiliza uma imagem que remete inequivocamente para a ideia da construção de um auto-retrato, ao identificar a obra poética com uma "verónica sangrenta de mim e dos tempos". ${ }^{7}$ De resto, o título que em definitivo reunirá a sua poesia - Poeta Militante (e não Poesia Militante, importa sublinhar) aponta precisamente para a tensão entre presença e ausência que define o auto-retrato, do qual a verónica, ao presentificar a imagem daquele que se ausentou, é o exemplo por excelência.

\footnotetext{
${ }^{6}$ BEAUJOUR, 1972, p. 9.

7 FERREIRA, 1972, p. 119.
} 
Em A Memória das Palavras, todo o percurso de escrita anterior a 1931 é também associado a uma consciência sofrida da descontinuidade entre o autor (que ainda não se reconhece como poeta) e a poesia (que não acontece ainda reconhecidamente como um acto de poeta). Essa seria mesmo a razão do título do livro Longe:

De repente sustive a leitura transido. «E eu?" - interroguei-me. «Sim. E eu?" "Que raio de mundo de versos era aquele tão longe do que eu sonhava e rangia em carne e lama? Que diabo de mundo era aquele tão longe, longe de mim? Sim, tão longe..."

Espera!...Longe!... Peguei num lápis e desenhei no mármore da mesa em letras de imitação tipográfica: L O N G E.

E porque não? Chamar-se-ia Longe. Aliás uma palavra carregada de nevoeiro, de ausência e tardinha. (...) Para quando o Perto?)

(...) "Que publicaria a seguir? Outro livro sem mim? (...), 8

Como faz notar Michel Beaujour, em literatura, o auto-retrato é sempre auto-retrato do escritor enquanto escritor; ${ }^{9}$ e, no caso de José Gomes Ferreira, sabemos até (e tudo isto faz parte do auto-retrato) que o próprio nome de poeta surge a 8 de Maio de 1931 na sequência da composição do poema que começa "O Sol é sempre o mesmo e o céu azul / ora é azul, nitidamente azul / ora cinzento, negro, quase-verde... / Mas nunca tem a cor inesperada". ${ }^{10}$ É este poema, apontado como aquele em que o poeta encontra "o [seu] tom de tinir autêntico", "a naturalidade de expor as monstruosas realidades simples do dia-a-dia, como se se tratasse de descobertas absurdas, através dum colóquio de imagens e de palavras de valorização nova", ${ }^{11}$ o primeiro a ser assinado "com um "José" bem nítido e sexuado a anteceder o "Gomes Ferreira" que subscrevera os dois títulos de juventude: "Eu enfim completo. (...) Eu, José Gomes Ferreira, nascido na noite de 8 de Maio de 1931, pasmado de ter voz...."12

\footnotetext{
${ }^{8}$ FERREIRA, 1972, p. 89.

${ }^{9}$ BEAUJOUR, 1980, p. 448.

${ }^{10}$ FERREIRA, 1972, p. 176. Trata-se do poema "Viver sempre também cansa", que abre o primeiro volume de Poeta Militante.

${ }^{11}$ FERREIRA, 1972, p. 177.

${ }^{12}$ FERREIRA, 1972, p. 178.
} 
Por conseguinte, a crer no testemunho dado em A Memória das Palavras, livro cujo subtítulo é "ou o gosto de falar de mim" (e parece claro que o pronome pessoal "mim" designa aqui o poeta que se inventa sob a fórmula do auto-retrato), o nome, o poeta e a poesia teriam nascido simultaneamente, ou, talvez seja mais exacto dizer assim, teriam nascido em cadeia: perante esse poema, o autor ter-se-ia reconhecido a si mesmo como poeta e firmaria esse reconhecimento modificando definitivamente a sua assinatura inicial. Daí por diante, a circularidade entre eu (sujeito de enunciação) e mim (auto-representação enquanto poeta que essa voz instaura e passa a poder comentar) está estabelecida e com ela a possibilidade do auto-retrato.

De resto, não é possível ler a poesia de José Gomes Ferreira sem pensar no processo de enunciação que lhe dá origem. Para um escritor que se pretende antes de mais poeta e que diz valorizar, acima do poema, o que chama "o acto da (...) poesia",13 a questão da escrita só pode colocar-se como uma poiesis que supõe um sujeito construído como uma identidade literária. Escrita frequentemente na primeira pessoa, essa poesia sempre supõe um sujeito que, mais do que apresentar-se como uma voz, se apresenta rigorosamente enquanto poeta e, nessa medida, como autor. Tal como Montaigne, também José Gomes Ferreira poderia ter dito que era a si mesmo que "pintava" nos seus versos, embora a posição simultaneamente intra e extratextual desta assinatura seja uma das questões que suscitam reflexão. A explicação de que Montaigne faz preceder os Ensaios, e que converge na conhecida equação "je suis moymesmes la matiere de mon livre", é mesmo aproximável do subtítulo que acompanha os volumes de Poeta Militante - "Viagem do Século Vinte em mim". ${ }^{14}$ Em ambos os casos, a escrita institui como sujeito um eu que é simultaneamente objecto do discurso, neste caso enquanto poeta, e a sua existência advém assim inseparável do próprio acto de escrita.

É aliás significativo que, excepção feita de duas obras de juventude, Lírios do Monte (1918) e Longe (1921) - assinadas ainda de modo "impessoal, à século XIX" com um mero "Gomes Ferreira", ${ }^{15}$ isto é, ainda

\footnotetext{
${ }^{13}$ FERREIRA, 1991, p. 162.

${ }^{14}$ Itálico meu.

${ }^{15}$ FERREIRA, 1972, p. 178.
} 
atribuíveis a um outro que não o poeta nascido em 1931 -, os títulos que acompanham os livros de poesia a partir de 48 sempre convoquem a figura do poeta, embora sob duas modalidades diferentes. O primeiro - Poesia (I, II, III, IV e V) -, usado entre 1948 e 1973, estabelece essa relação de modo indirecto, na medida em que é o facto de esse título preencher apenas muito vagamente a função identificadora da obra que leva a convocar o nome do autor. A plena identificação desses volumes exige uma designação que complemente o carácter muito genérico do título e leva a que falemos deles como a Poesia (I ou II, etc.,) de José Gomes Ferreira. O segundo título poderia parecer a evolução natural deste. Em Poeta Militante, título que, usado a partir de 1977, virá a designar a totalidade da obra poética, a figura do poeta apropria-se dessa função designativa e afirma inequivocamente a sua presença. Unindo título e subtítulo reconhece-se a formulação característica do auto-retrato: "[eu], poeta militante, [vou falar da] viagem do século XX em mim”, ou seja, eu sou a matéria do meu livro.

De acordo com A Memória das Palavras, este segundo título teria na verdade surgido ainda antes do primeiro, uma vez que dataria de 1947 a invenção da "teoria do Poeta Militante", bem como o baptismo com esse nome do conjunto dos "Diários em verso, escritos ao longo de quinze anos de gaveta", ${ }^{16}$ isto é, desde o celebrado ano de 1931. José Gomes Ferreira não teria adoptado de imediato esta expressão para título da sua obra apenas por temer "que se gerasse qualquer equívoco de restrição provocado pelo termo militante por demais ligado à ideia de actividades políticas e religiosas"; ${ }^{17}$ no entanto, a formulação da "teoria do Poeta Militante" acompanha a preparação da edição de Poesia - I e surge do reconhecimento da existência de uma relação inextricável entre poesia e circunstancialidade, num sentido que abrange quer acontecimentos políticos de fortes repercussões nacionais e mundiais quer acontecimentos aparentemente irrelevantes como "o pontapé numa pedra, o medo de atravessar o corredor às escuras, a flor pisada (...), e principalmente essa coisa nenhuma "que é o alimento dos poetas vorazes"". ${ }^{18}$

\footnotetext{
${ }^{16}$ FERREIRA, 1972, p. 187-8.

${ }^{17}$ FERREIRA, 1972, p. 183.

${ }^{18}$ FERREIRA, 1972, p. 193.
} 
Tão atenta ao quotidiano mais imediato ou pessoal como aos grandes acontecimentos político-sociais que marcaram o século XX, a obra poética de José Gomes Ferreira abarca um campo de enorme diversidade, encontrando como condição de unidade precisamente o auto-retrato do poeta militante, sendo este último entendido como "um homem que cumprisse apenas o ofício natural da sua missão de reagir poeticamente perante a vida" 19 e que se retratasse a si mesmo enquanto oficial desse ofício, isto é, integralmente como poeta. Obras como A Memória das Palavras, Relatório de Sombras, Imitação dos Dias, O Mundos dos Outros e até O Irreal Quotidiano, servem o propósito característico daquele que se auto-retrata como escritor: "je vais vous montrer, en commentant mes propres textes, comment j'en suis arrivé à être ce que je suis". ${ }^{20}$

\section{3.}

Situar a formulação da "teoria do Poeta Militante" em 1947 equivale a situá-la por referência a um momento de grande proximidade entre José Gomes Ferreira e os poetas neo-realistas, que o mesmo é dizer um momento de particular atenção pela questão do compromisso social do escritor e pela relação entre poesia e testemunho. Todavia, no final da década de 40, também são já perceptíveis os perigos inerentes a uma leitura simplista ou excessivamente funcionalista do papel da poesia no quadro do Neo-realismo. Ora o auto-retrato permite a José Gomes Ferreira resolver de um só lance, através de uma articulação extremamente original, tanto a necessidade de comprometimento com o seu tempo e as circunstâncias como a manutenção de um conceito de poesia inseparável do sonho, da evasão e do devaneio. Apesar da justificação dada em $A$ Memória das Palavras para o uso do adjectivo "militante" - o termo aludiria simplesmente a um "militante da poesia total", que o escolheria na convicção de que "assim dilatava a matéria cantável" que a expressão "Poeta Militante" procurasse responder também a uma

\footnotetext{
${ }^{19}$ FERREIRA, 1972, p. 194.

${ }^{20}$ BEAUJOUR, 1980, p. 121.

${ }^{21}$ FERREIRA, 1972, p. 188.
} 
necessidade consciente de comprometimento social e político. Apesar de fazer parte do auto-retrato do poeta militante a afirmação de que "o poeta tem deveres mais profundos e terriveis como poeta do que como cidadão" 22 e a recusa de escrever por imposição exterior ("(...) eu nunca receberia ordens de ninguém para cantar. De ninguém - ouviram?"), ${ }^{23}$ "a coincidência do poeta com o Grupo" ${ }^{24}$ é encarada também como uma das formas de liberdade criadora.

Como conciliar este absoluto desejo de liberdade, o gosto pela efabulação, pela fantasia e o sonho, com a necessidade de solidário empenhamento tantas vezes tematizada na obra, até pela recorrência da palavra "remorso"? - Julgo que a síntese dialéctica que permite a coexistência destes dois movimentos de sinal contrário consiste precisamente na construção do auto-retrato enquanto poeta militante. Repare-se que o poeta militante é também um "poeta andante" (expressão na qual ecoa uma alusão quixotesca que reitera a contradição que acabo de referir), ou seja, um poeta em permanente movimento pela cidade, entre a cidade e o campo, atento a tudo o que o rodeia, numa deambulação que faz pensar em Cesário Verde, até pelo modo como se combina com um olhar transfigurador:

(passeio por um bairro pobre de Lisboa)

Deslumbramento

desta manhã mil vezes repetida

com o ouro das mãos do sol

a apalparem o vento,

o vento-fêmea que se despe num lençol

e nos seios da roupa estendida.

Peles de cadáveres que uma volúpia branca desespera

- enforcados pela cólera da Primavera. ${ }^{25}$

\footnotetext{
${ }^{22}$ FERREIRA, 1970, p. 126.

${ }^{23}$ FERREIRA, 1970, p. 127.

${ }^{24}$ FERREIRA, 1970, p. 127.

${ }^{25}$ FERREIRA, 1991, p. 74.
} 
Um dos elementos essenciais na construção do auto-retrato passa precisamente pelo facto de ele permitir a integração do poder transfigurador da poesia no quotidiano de uma vida de poeta:

No desejo de persistir através de tudo, tornei-me em poeta de intervalos, teimoso, improvisador, infatigável, "Oculto na simulação de escutar os amigos sem os ouvir e disfarçado de atento por fora para moer nuvens à minha vontade. Poeta em casa, na cama, no quarto de banho, nos empregos, nos cafés, nos concertos, nos sarilhos do trânsito e, sobretudo, na vagabundagem nocturna e nos eléctricos" (revelava eu na (...) entrevista). ${ }^{26}$

Neste contexto, falar de si implicará forçosamente falar dos outros, do "mundo dos outros", o que inclui a referência precisa a acontecimentos social e politicamente relevantes; mas permitirá fazê-lo no modo lírico, que se coaduna perfeitamente com um registo efabulatório. Através do auto-retrato, o sujeito de enunciação torna-se situado, e o poema pode dar-nos simultaneamente o motivo que desperta a atenção do poeta e o efeito transfigurador que é a sua maneira de olhar para o mundo. É aí que entram os parênteses característicos da poesia de José Gomes Ferreira, "as famosas epígrafes que me desmascaram e ocultam", como são referidas em Relatório de Sombras. ${ }^{27}$ Por eles, ficamos a saber que a visão mais feérica foi suscitada pelo mais insignificante acontecimento quotidiano ou então pela vivência atenta de acontecimentos politica e socialmente relevantes. Pelos volumes de Poeta Militante perpassa o século XX: o Fascismo, a Guerra Civil de Espanha, a Segunda Guerra Mundial, as prisões políticas, a vida literária lisboeta, os jornais, o cinema... mas tudo isto só é possível porque a poesia se deixa atravessar por um autor textual, isto é, o poeta militante que se insinua como um sujeito biográfico.

A "Aventura" contada em A Memória das Palavras é a história da descoberta desta estratégia poética: "O desajuste entre mim, a minha Poesia e a Vida findara para sempre, para sempre!", ${ }^{28}$ resume o poeta militante perante a escrita que o fizera aparecer a si mesmo, como se a aparição da poesia supusesse a coincidência do sujeito de enunciação

\footnotetext{
${ }^{26}$ FERREIRA, 1972, p. 196.

${ }^{27}$ FERREIRA, 1972, p. 120.

${ }^{28}$ FERREIRA, 1972, p. 208.
} 
poética com o poeta José Gomes Ferreira. "Finalmente, mundo! Finalmente entre mim e a época não sangrava qualquer sebe de discórdia". ${ }^{29} \mathrm{O}$ auto-retrato permitira colocar primeiro a poesia na vida, como vivência de poeta e modo transfigurador de olhar o mundo que há à procura de um mundo por haver, para permitir, depois, o desenvolvimento de uma aproximação circunstancial sem quaisquer custos para o Sonho. Adivinha-se a lição de Raul Brandão, o Mestre Secreto tantas vezes revelado por José Gomes Ferreira, não só neste modo de integrar o Sonho como uma das dimensões da vida, mas também porque o auto-retrato pressupõe a exploração expressionista da interioridade como condição de autenticidade estética. Tal como em Raul Brandão, o "gosto de falar de mim" será uma estratégia para chegar ao "mundo dos outros", isto é, uma forma original, porque muito mais efabulatória, de desenvolver o lirismo coral característico dos poetas neo-realistas.

\section{4.}

Dir-se-ia que, fazendo confluir uma matriz brandoniana e uma matriz pessoana, o auto-retrato se constrói através de um jogo permanente com o leitor. "Só nunca fui uma coisa: eu próprio" - lemos num dos textos de O Mundo dos Outros. "Mas esse é um dos muitos segredos que hei-de levar para a sepultura". ${ }^{30}$ Todavia, já em Imitação dos Dias se regista um "Apontamento" de sinal contrário: "Uma das minhas virtudes "oficiais" é a sinceridade (que comédia!), mesmo à custa da pele arrancada com tenazes diante do público - sobretudo diante do público. Lá mentir a mim mesmo ou iludir-me, nunca! Tira-me o gosto de viver. Antes uma cama de espinhos". ${ }^{31}$ E para exemplificar a pouca sinceridade de tanta sinceridade, surge mais uma confissão: "Por exemplo: descobri que a insistência demasiada na enumeração das minhas fraquezas não passa de um estratagema de vaidade engenhosa". Ora, curiosamente, em Relatório de Sombras, a mesma descoberta é apresentada como uma inesquecível

\footnotetext{
${ }^{29}$ FERREIRA, 1972, p. 217.

${ }^{30}$ FERREIRA, 1972, p. 32.

${ }^{31}$ FERREIRA, 1970, p. 74.
} 
lição recebida de um amigo de café: "TRANSFORME OS SEUS DEFEITOS EM VIRTUDES", teria ele aconselhado:

- Mas como? - murmurava eu, aprendiz de olhos famélicos.

E então o meu explicador propunha-me a alquimia necessária, com esta exemplificação que nunca mais esqueci:

Diga-me: você é medroso, não é verdade? Tem cara disso.

- Sim. Muitíssimo. Tenho um medo dos diabos! Até de fantasmas.

- Pois bem. Não o esconda. Aproveite o medo. Explore-o! Mostre-o bem. Confesse-o em voz bem nítida nos versos e verá como passará por herói! E valente.

Assim fiz, meio século depois, e - ó Apolo dos antigos! - como o meu mestre tinha razão. ${ }^{32}$

A palinódia e a auto-ironia são constantes em José Gomes Ferreira e, ao passar de livro para livro, o leitor acaba por justificar as frequentes contradições pelo trânsito permanente entre um presumível sujeito biográfico que se ficcionaliza e o sujeito ficcional assim constituído, sem nunca poder decidir quem é quem, afinal, tanto mais que uma das dimensões da auto-ironia passa pela reflexão metatextual e intertextual. Perante esta espécie de efeito especular, em que o poeta se auto-retrata no próprio acto de escrever, o leitor só pode hesitar quanto à possibilidade de se estabelecer um "pacto autobiográfico". "Essencial: a sinceridade, em mim, não se pode desligar da ironia", lê-se no primeiro volume do Diário, e logo a seguir surge uma nota com "[o]utra forma de iludir a sinceridade" que passa por "revelar cruelmente os sentimentos (...) mas evitar a narrativa de factos". ${ }^{33}$

Apesar da referência aos "Diários em verso", corroborada pela ordenação cronológica que organiza os títulos reunidos nos volumes de Poeta Militante, não faria sentido atribuir um sentido simplesmente diarístico à poesia de José Gomes Ferreira, porquanto esses livros não formam uma narrativa seguida, ${ }^{34}$ sobretudo no que respeita ao sujeito. Entre os poemas e mesmo entre a poesia e as obras que suportam o auto-

\footnotetext{
${ }^{32}$ FERREIRA, 1972, p. 35-36.

${ }^{33}$ FERREIRA, 1990, p. 130.

${ }^{34}$ BEAUJOUR, 1980, p. 8.
} 
retrato do poeta militante estabelece-se, de facto, aquele sistema de remissões, reiterações, sobreposições e correspondências de elementos homólogos e permutáveis que Michel Beaujour considera distinguir o auto-retrato da autobiografia. ${ }^{35}$ A sintagmática narrativa constrói-se em sequências autónomas, mas, no que respeita ao sujeito desta "enunciação escrevente", ${ }^{36}$ o texto funciona essencialmente por montagem e obriga o leitor a um esforço aturado de correlação e combinação. Assim, tudo indica que a aparência diarística, quando existe, está na verdade ao serviço da construção de um auto-retrato. O sujeito reflecte sobre a sua autorepresentação tal como o texto reflecte sobre si mesmo formando o que Louis Marin chama um "drapeado", uma vez que os lugares e a tópica da enunciação são simultaneamente figuras do texto, elementos da urdidura de suporte do texto. ${ }^{37}$ Ao inscrever no interior do texto o nome José Gomes Ferreira, aquele com que também são assinados os livros, o poetamilitante-andante, compromete-se com um mundo que "há-de ser outro"38 e com "as lágrimas dos outros", ${ }^{39}$ simulando deixar a poesia inteiramente livre de compromissos e contingências. Porém, o resultado esperado é exactamente o oposto. O poeta militante auto-retrata-se enquadrado na paisagem do século XX, junto dos outros e ciente de que, quanto mais falar de si neste contexto maior será, afinal, o poder de generalização da sua poesia. E o leitor, por sua vez, sabe também que a sinceridade é aqui uma figura e que essa "verónica sangrenta de mim e dos tempos" apenas lhe apresenta uma certa imagem-de-poeta com a qual o poeta José Gomes Ferreira acabaria por ficar parecido.

\footnotetext{
${ }^{35}$ BEAUJOUR, 1980, p. 9.

${ }^{36}$ MARIN, 1989, p. 142.

${ }^{37}$ MARIN, 1989, p. 142.

${ }^{38}$ FERREIRA, 1990, p. 105.

${ }^{39}$ FERREIRA, 1990, p. 115.
} 


\section{Referências Bibliográficas}

BEAUJOUR, Michel. Miroirs d'encre. Paris: Editions du Seuil, 1980.

BUESCU, Helena Carvalhão. Em busca do autor perdido. Lisboa: Cosmos, 1998.

BUESCU, Helena Carvalhão. Sujeito, voz e ficcionalização nos Sonetos Completos de Antero de Quental. In: A lua, a literatura e o mundo. Lisboa: Cosmos, 1994.

FERREIRA, José Gomes. A memória das palavras (1965). 3. ed. Lisboa: Portugália, 1972.

FERREIRA, José Gomes. Dias Comuns (III). Lisboa: Dom Quixote, 1991.

FERREIRA, José Gomes. Dias comuns (I). Lisboa: Dom Quixote, 1990.

FERREIRA, José Gomes. A imitação dos dias (diário inventado) (1966). 2. ed. Lisboa: Portugália Editora, 1970.

FERREIRA, José Gomes. Poeta Militante(II). Lisboa: Dom Quixote, 1991.

FERREIRA, José Gomes. Poeta militante (I). 4. ed. Lisboa: Dom Quixote, 1990.

FERREIRA, José Gomes. Relatório de Sombras ou A Memória das Palavras II. Lisboa: Moraes Editores, 1980.

FERREIRA, José Gomes. Parece impossível mas sou uma nuvem. In: O mundo dos outros, histórias e vagabundagens. 4. ed. Lisboa: Portugália Editora, 1972. MARIN, Louis. Topique et figures de l'énonciation. La Par de l'Oeil, v. 5, p. 142, 1989.

SILVA, Vítor Manuel de Aguiar e. Teoria da Literatura. 6. ed. Coimbra: Almedina, 1984. 


\section{Resumo}

Propõe-se abordar criticamente a construção do auto-retrato de José Gomes Ferreira enquanto poeta militante, construção que se encontra disseminada em várias de suas obras.

\section{Abstract}

This essay tries to analyse the poetry of José Gomes Ferreira as a representation of a combative poet. 